condicionar o funcionamento de estabelecimentos à emissão de licença, visa o controle da atividade em questão. Muitas vezes, as alegaçōes que surgem por parte desses estabelecimentos, para justificar a não-solicitação da mesma, prendem-se a argumentos de ordem meramente administrativa, tentando desqualificar a exigência.

Por esse motivo é preferível que a lavratura de autos de infração ou de imposição de penalidades apóie-se também no enquadramento das irregularidades em dispositivos de lei que enfatizem a questão do risco. Isso facilita grandemente as respostas aos recursos normalmente interpostos e, em casos como este, enriquece o processo com argumentos de difícil contestação pelo infrator.

\title{
REFERÊNCIAS
}

(1) Resolução CNEN n. 4/89, publicada no DOU de 9.5.89.

(2) Recomendações da Comissão Internacional de Proteção Radiológica (ICRP) - Publicação n. 26, de 1977.

(3) Norma CNEN-NE-3.01 "Diretrizes Básicas de Radioproteção", publicada pela Resolução CNEN n. 12/88, DOU de $1^{2} .8 .1988$.

\section{PODER DE POLÍCIA E EXIGIBILIDADE DA CONTRATAÇÃO DE PROFISSIONAL HABILITADO, IMPOSTA Ȧ INSTITUIÇÃO DESTINADA AO ABRIGO DE IDOSOS}

$3^{\text {a }}$ Vara de Presidente Prudente

Autos n. 1999.61.12.008340-9

Mandado de Segurança

Vistos,

ASSOCIAÇÃO DO ASILO VICENTINO NOSSA SENHORA DA PENHA DE PIRAPOZINHO, impetrou mandado de segurança contra ato da SRA. COORDENADORA FISCAL DA SUBSEÇÃO DE PRESIDENTE PRUDENTE DO CONSELHO REGIONAL DE ENFERMAGEM DE SÃO PAULO, que ex- 
pediu-Ihe notificação para enviar ao COREN a relação do pessoal que presta cuidados diretos aos idosos, com qualificação completa no prazo de 20 dias; manter profissional enfermeiro para assumir direção, coordenação, planejamento, supervisão e avaliação das ações de enfermagem na instituição, durante todo o período de funcionamento, de imediato; e manter profissional técnico de enfermagem para executar ações invasivas e de risco na unidade, de imediato. Postula liminar para afastar os efeitos da referida notificação. Pede os benefícios da justiça gratuita.

Com a inicial vieram os documentos de fls. 19/48.

Foram deferidos a liminar e o benefício da justiça gratuita (fls. 50).

A impetrada prestou informações (fls. 54/63).

O Ministério Público opinou pela concessão da segurança (fls. 83/95).

É o relatório.

DECIDO.

A Lei n. 7.498/86 e o Decreto n. 94.406/87 regulamentam a atividade profissional do enfermeiro, conferindo ao COREN atribuição para fiscalizar o "exercício profissional", mas não contêm determinação expressa que o autorize a exigir de estabelecimento hospitalar que contrate profissional para chefiar equipe de enfermagem. Se a lei não o exige, não pode simples portaria ou resolução fazê-lo, já que ninguém será obrigado a fazer ou deixar de fazer alguma coisa senão em virtude de lei.

Por outro lado, a lei prevê punições de ordem administrativa para coagir profissionais e empresas que se encontram em situação irregular, podendo a impetrada requerer às autoridades públicas competentes a aplicação de tais medidas repressivas aplicáveis à hipótese, conforme precedentes do Tribunal Regional Federal da $1^{2}$ Região:

Ementa:

ADMINISTRATIVO. CONSELHO REGIONAL DE ENFERMAGEM. MEDIDA JUDICIAL PARA COMPELIR ESTABELECIMENTO HOSPITALAR A CONTRATAR ENFERMEIRO PARA DIRIGIR SUA EQUIPE DE ENFERMAGEM. FALTA DE PREVISÃO LEGAL.

RESOLUÇÃO SEM FORÇA VINCULANTE. INADMISSIBILIDADE. ILEGITIMIDADE ATIVA AD CALISAM RECONHECIDA. HONORÁRIOS DE ADVOGADO EM PERCENTUAL SOBRE O VALOR DA CAUSA QUANDO NĀO HOUVER CONDENAÇÃO. LEGITIMIDADE. 
1. INEXISTINDO PREVISÃO LEGAL A AUTORIZAR CONSELHO REGIONAL DE ENFERMAGEM A EXIGIR QUE ESTABELECIMENTO HOSPITALAR CONTRATE ENFERMEIRO PARA DIREÇÃO DE SUA EQUIPE DE ENFERMAGEM, SIMPLES RESOLUÇÃO NĀO PODERIA FAZÊ-LO PORQUE "NINGUÉM SERÁ OBRIGADO A FAZER OU DEIXAR DE FAZER ALGUMA COISA SENÃO EM VIRTUDE DE LEI" (CONSTITUIÇÃO FEDERAL, ART. 5, II).

2. QUANDO não HOUVER CONDENAÇÃO SERÁ LÍDIMO AO JUIZ ESTABELECER OS HONORÁRIOS DE ADVOGADO EM PERCENTUAL SOBRE O VALOR DA CAUSA. (TRF/1. REGIÃO - AC N. 94.01.30890-0/MG, 1. TURMA - UNÂNIME - JULGAMENTO 12.12.95.)

3. ILEGITIMIDADE ATIVA AD CAUSAM RECONHECIDA.

4. APELAÇÃO DENEGADA.

5. SENTENÇA CONFIRMADA.

EMENTA:

ADMINISTRATIVO. REGISTRO NO COREN-DEF. CLÍNICA. AÇÃO COMINATÓRIA. DESCABIMENTO. LEIS NS. 6.839/80 E 6.437/77.

I. A LEGISLAÇÃO PREVÊ INFRAÇÕES SANITÁRIAS, DE ORIGEM ADMINISTRATIVA, COMO MEIO DE COAGIR OS PROFISSIONAIS E EMPRESAS QUE ATUAM EM SITUAÇÃO IRREGULAR. PODE O CONSELHO REGIONAL DE ENFERMAGEM AGIR, REQUERENDO ÀS AUTORIDADES PÚBLICAS A APLICAÇÃO DO ARSENAL DE MEDIDAS REPRESSIVAS DIRETAS E INDIRETAS QUE A LEI LHES CONFERE, MAS DENTRO DESSES LIMITES.

II. INCABÍVEL, NO ENTANTO, AÇÃO COMINATÓRIA PARA COMPELIR-SE A EMPRESA IRREGULAR A INSCREVER-SE, SOB PENA DE MULTA DIÁRIA, NO ÓRGÃO PROFISSIONAL DE CLASSE.

III. APELAÇÃO A QUE SE NEGA PROVIMENTO.

Sem previsão legal para a notificação combatida, caracterizada está a lesão ao direito líquido e certo do impetrante.

Ante o exposto, acolho o pedido inicial e concedo a segurança, confirmando a liminar deferida.

Sem honorários advocatícios (Súmula n. 105 do STJ). Sem custas, em razão da justiça gratuita deferida. 
Sentença sujeita ao reexame necessário.

P.R.I.

Presidente Prudente, 25 de janeiro de 2000.

Newton José Falcão

Juiz Federal Substituto

COMENTÁRIOS

Osmir Antonio Globekner")

\section{A QUESTÃO CONTROVERSA E SUA RELAÇÃO COM O DIREITO SANITÁRIO}

A questão controversa é a da competência do Conselho Regional de Enfermagem para expedir notificação, ou impor sanções, nos termos em que o fez relativamente ao asilo para idosos. $O$ deslinde da questão acima seria suficiente para a solução da lide, como efetivamente o foi. Porém, considerando o nosso escopo, o de entender como os temas afetos ao Direito Sanitário penetram e permeiam a lide, poderiamos também discutir a obrigatoriedade ou exigibilidade da presença de profissional da enfermagem nesse tipo de instituição, à luz da legislação sanitária e protetora do idoso. Nessa discussão apreciar o teor da Portaria 810 do Ministério da Saúde e o enquadramento da instituição analisada entre aquelas que obrigatoriamente exercem serviços de saúde. E poderíamos mais, estender a questão para discutir e apreciar a conveniência ou legitimidade do tipo de exigência que analisamos, à luz dos princípios constitucionais que a informam. Discutir a participação, o papel e a responsabilidade da sociedade e do Estado na prestação dos serviços de saúde e no amparo e assistência devidos ao idoso. No fundo, a questão da colaboração com o Estado versus o controle pelo Estado. Acreditamos serem tais questões aquelas, pertinentes ao Direito Sanitário, que estão a envolver, próxima ou remotamente, o conflito que foi levado à apreciação judicial.

(*) Engenheiro Quimico, Bacharel em Direito e Especialista em Direito Sanitário. 


\section{A COMPETÊNCIA DO COREN}

A questão foi bem equacionada e decidida no caso concreto. Inquestionavelmente, em face da legislação vigente, falece competência aos Conselhos Regionais, em primeiro lugar para impor os comportamentos que busca impor na notificação expedida, em segundo lugar para aplicar as sanções do tipo aventado no caso. $\dot{E}$ abundante e uniforme a jurisprudência a respeito.

A fiscalização é atividade do poder de polícia investido no Estado, e pelo fato mesmo de condicionar e limitar a liberdade e a propriedade, direitos fundamentais do indivíduo, deve estar rigidamente adstrita à letra da lei, não podendo o seu regulamento inovar, acrescendo, esses limites e condicionamentos. Esta é uma das expressões do Princípio da Legalidade em nosso Direito.

Por primeiro, teriamos de extremar a fiscalização do exercício profissional da fiscalização sanitária. Esta cabendo aos órgãos competentes para tanto, como reconhece o próprio Conselho Regional, utilizando o argumento até para afastar 0 periculum in mora que fundamenta a concessão da liminar, uma vez que, não cabendo ao COREN a aplicação, não haveria a iminência de serem adotadas as medidas contra as quais se insurge a impetrante.

O fato é que a lei de regência da atividade do Conselho não prevê as medidas punitivas com as quais o órgão acena na notificação. $E$ a legislação que a prevê, a Lei n. 6.437/77, é de aplicação privativa pela autoridade sanitária, salvo delegação por meio de convênio, a teor inclusive do disposto no art. 14 da mesma lei.

Caberiam, sob outro fundamento legal, as exigências e sanções aventadas? Vejamos.

No que tange às condutas exigidas, a Lei n. 7.498/86, que regulamenta as atividades de Enfermagem, prescrevendo as atividades que Ihes são privativas, em nenhum momento autoriza os respectivos conselhos a exigirem a contratação de profissional enfermeiro, mesmo às instituições às quais, pela própria natureza das suas atividades, o exercicio da enfermagem é inerente. A Resolução $n$. 146 do COFEN, em seus artigos $1^{2}$ e $2^{2}$, exorbita da sua esfera ao estabelecer de forma diversa. $E$ a jurisprudencia uniforme dos Tribunais Regionais Federais e do STJ. A exemplo:

"Inexistindo previsão legal a autorizar Conselho Regional de Enfermagem a exigir que estabelecimento hospitalar contrate enfermeiro para direção de sua equipe de enfermagem, simples Resolução nāo poderia fazê-lo porque 'ninguém será obrigado a fazer ou deixar de fazer algu- 
ma coisa senão em virtude de lei'. (Constituição Federal, art. 5, II.)" (TRF 1 Região - PRIMEIRA TURMA, DJ DATA: 09/09/1996 PAGINA: 66130 Relator JUIZ CATÃO ALVES).

“A Lei n. 7.498/86 não impõe a estabelecimento hospitalar a contratação de enfermeiro para gerenciar unidade de enfermagem. Precedentes do Tribunal. 2. Apelação desprovida" (TRF - 1 R., 3 $3^{\text {a }}$ T. Suplementar, DJ 22.10.2001, p. 781. Relator Juiz Evandro Reimão Dos Reis (conv.).

“... Os atos necessários a coibir o exercício da profissão de enfermeiro por quem não está habilitado, ultrapassam os limites de atos exercidos sob o manto regular do poder de policia" (TRF $-1^{\text {a }}$ R., $2^{\mathrm{a}}$ T., DJ 29.5.2000, p. 224. Relator Juiz Carlos Moreira Alves).

No que tange às sanções pretendidas, a lei de regência dos ConseIhos, Lei n. 5.905/73, autoriza a fiscalização e disciplina do exercício profissional, art. 15, II. No que se refere às penalidades, prevê, no art. 18, aquelas próprias ao mister acima, quais sejam: I - advertência verbal; II - multa; III - censura; IV - suspensão do exercício profissional; V - cassação do direito ao exercicio profissional. A regulamentação infralegal dessas atividades obviamente não pode extrapolar os limites concessivos da lei. A resolução CONFEN n. 158, que normatiza o funcionamento do Sistema de Disciplina e Fiscalização do Exercício Profissional, ao referenciar empresas e estabelecimento de assistência de enfermagem, o faz no sentido da orientação, ou representação ante a autoridade competente. Prevê a instauração do Processo Administrativo, julgamento e aplicação de penalidade relativamente às empresas, art. $3^{\circ}, 11$, "a". Bem como, no art. $6^{\circ}$, que, "mediante poder de polícia administrativa da Autarquia, utilizando-se do atributo de autoexecutoriedade do ato administrativo, impedirá o exercício de Enfermagem que esteja pondo em risco a segurança e a saúde da população, observados os ditames da legislação vigente". O que poderia, em tese, ser o caso em apreço.

A legislação apresentada, no entanto, volta-se, por um lado, sempre para o exercício profissional, legal ou ilegalmente, porém efetivamente, praticado. Por outro lado se volta para estabelecimentos que estejam a ele ligados e obrigados ao registro no órgão respectivo pelo critério da atividade básica, conforme a Lei n. 6.839/80.

"O critério definidor de obrigatoriedade de registro de empresas e da anotação dos profissionais legalmente habilitados, delas encarregados, nos conselhos de fiscalização das profissões, assenta-se na atividade básica da empresa, ou firma-se em relação à natureza dos serviços que a empresa presta a terceiros, a teor da Lei n. 6.839/80". (TRF - $1^{\text {a }}$ R., 1 T., DJ 25.9.2000, p. 9. Relator: Juiz Aloisio Palmeira Lima.) 
"somente a empresa privada que tenha como atividade básica a prestação de serviço de enfermagem e/ou medicina, está obrigada à inscrição no conselho regional de enfermagem..." (TRF 5ª R., $2^{\mathbf{a}}$ T., DJ 25.10.1996, p. 81760. Relator: Juiz Petrucio Ferreira).

"Casa de parto que não desenvolve atividade típica, e nem presta serviços a terceiros na área de enfermagem, não está obrigada 'em tese' a se inscrever no conselho regional de enfermagem" (TRF $5^{\mathrm{a}} \mathrm{R}$., $2^{\mathrm{a}} \mathrm{T}$., DJ 19.12.1997, p. 111963. Relator Juiz Élio Wanderley de Siqueira Filho (Substituto).

"A legislação prevê infraçōes sanitárias, de ordem administrativa, como meio de coagir os profissionais e empresas que atuam em situação irregular. Pode o Conselho Regional de Enfermagem agir, requerendo às autoridades públicas a aplicação do arsenal de medidas repressivas diretas $e$ indiretas que a lei lhes confere, mas dentro desses limites" (TRF - 1 R., 1 ${ }^{\text {a }}$ T., DJ 10.6.1996, p. 38837. Relator Juiz Aldir Passarinho Junior).

"Sendo a atividade principal do asilo o internamento e a manutenção de pessoas idosas, a prática secundária de atividades de fisioterapia não o obriga a registrar-se no Conselho Regional de fisioterapia e Terapia

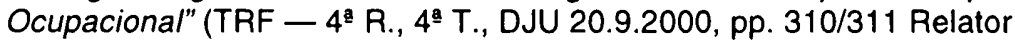
Juiz Zuudi Sakakihara).

Dessa forma temos, por um lado, que não há previsão para que os Conselhos Regionais de Enfermagem exijam, a quem quer que seja, a contratação de profissionais da categoria que lhes incumbe fiscalizar. Depois, se é certo que aos conselhos compete a fiscalização do profissional onde quer que este exerça suas atividades, o registro e a fiscalização de estabelecimentos estão condicionados ao critério da atividade básica, como acima exposto. Sem sombra de dúvida a atividade básica do Asilo Vicentino não é a prestação de serviços de saúde e tampouco a de assistência em enfermagem.

\section{A EXIGIBILIDADE À LUZ DA LEGISLAÇÃO SANITÁRIA E PROTETORA DO IDOSO}

Excluida a competência do órgão de fiscalização profissional para exigir a contratação de profissionais de enfermagem, passemos a verificar tal exigibilidade com suporte na legislação sanitária.

Aqui também cabe invocar o princípio geral da legalidade, pois que ninguém será obrigado a fazer ou deixar de fazer alguma coisa senão em virtude da lei, conforme o comando do art. $5^{\circ}$, II, da Constituição Federal. Porém, ao lado do princípio geral, temos, também, uma especificação do princípio, ainda no campo constitucional, mas no aspecto particular das ações 
e serviços de saúde, pois que, a teor do art. 197 da Constituição Federal, a sua regulamentação, fiscalização e controle pelo poder público dependerão de lei.

Não há dispositivo legal que imponha aos asilos destinados ao abrigo do idoso a manutenção permanente de profissionais de enfermagem.

É bem verdade que a Portaria 810, invocada pelo COREN, dirige-se a um amplo espectro de instituições, como em seu título:

"Casas de Repouso, Clínicas Geriátricas e outras Instituições de Atendimento ao Idoso",

ou aos especificar ou definir, de forma também bastante ampla, as instituições a que a norma se destina:

"Consideram-se como instituições especificas para idosos os estabelecimentos, com denominações diversas, correspondentes aos locais físicos equipados para atender pessoas com 60 ou mais anos de idade, sob regime de internato ou não, mediante pagamento ou não, durante um período indeterminado e que dispõem de um quadro de funcionários para atender as necessidades de cuidados com a saúde, alimentação, higiene, repouso e lazer dos usuários e desenvolver outras atividades características da vida institucional" (Portaria n. 810/89 do MS, item 1).

A Portaria impõe ademais, no item 1.2, a necessidade de direção técnica da Instituição por um profissional da área de saúde, para responder junto à autoridade sanitária. As instituições que tiverem como objetivo a prestação de atenção médico-sanitária aos idosos devem, de acordo com o item 1.2.1, contar em seu quadro funcional com um coordenador médico, sendo que a designação de especialização em geriatria e gerontologia deve obedecer às normas da Associação Médica Brasileira - ABM. Por fim, o diploma invocado pelo COREN, ao referir-se aos Recursos Humanos, no item 4, determina que "As instituições para idosos em geral devem conter:

- assistência médica - assistência odontológica - assistência de enfermagem - assistência nutricional - assistência psicológica assistência farmacêutica - atividades de lazer - atividades de reabilitação (fisioterapia, terapia ocupacional e fonoaudiologia) - apoio jurídico e administrativo - serviços gerais".

Especificando no item 4.2:

"O dimensionamento da equipe multiprofissional necessária à assistência ao idoso institucionalizado deverá se basear:

a) nas necessidades da população atendida;

b) nas disponibilidade de recursos humanos regionais ou locais;

c) nos critérios dos respectivos conselhos regionais de profissionais". 
Entender tal dispositivo como uma obrigação imposta a todas as instituições voltadas ao atendimento do idoso, de manter em tempo integral o profissional ligado a cada uma das área de assistência citada, parece uma interpretação improvável. Parece antes que a autoridade coatora extraiu em sua atuação, do texto normativo, significados mais amplos do que estaria autorizada a fazer, deixando de considerar inclusive o princípio da razoabilidade que deve informar as relações de Direito no âmbito administrativo.

Há que se considerar a natureza específica da assistência prestada pela instituição. A propósito, vejamos, já no campo das leis, o que se preconiza relativamente à assistência ao idoso. Temos a Lei n. 8.842/94, que dispõe sobre a política nacional do idoso. Esse diploma normativo, como não poderia deixar de ser, dado seu objeto, é marcado fundamentalmente por diretrizes programáticas, que revelam a filosofia adotada pelo legislador para disciplinar o atendimento ao idoso.

"Art. 10. Na implementação da política nacional do idoso, são competências dos órgãos e entidades públicos:

I - na área de promoção e assistência social:

a) prestar serviços e desenvolver ações voltadas para 0 atendimento das necessidades básicas do idoso, mediante a participação das familias, da sociedade e de entidades governamentais e não-governamentais.

b) estimular a criação de incentivos e de alternativas de atendimento ao idoso, como centros de convivência, centros de cuidados diurnos, casas-lares, oficinas abrigadas de trabalho, atendimentos domiciliares e outros;"

"Il — na área de saúde:

a) garantir ao idoso a assistência à saúde, nos diversos niveis de atendimento do Sistema Único de Saúde;

c) adotar e aplicar normas de funcionamento às instituições geriátricas e similares, com fiscalização pelos gestores do Sistema Único de Saúde;

h) criar serviços alternativos de saúde para o idoso (grifos nossos)."

Permeia todo o texto legal a idéia, de um lado, da cooperação entre diferentes setores da sociedade e do Estado. De outro, a de um atendimento 
sob formas variadas, multifacetado, inclusive com uma altenatividade de serviços e de instituições que os prestem.

$\mathrm{Na}$ alínea "c" do inciso II do art. 10, que transcrevemos acima, poderia residir a autorização legal para a disciplina que a Portaria n. 810 do MS provê. $O$ decreto regulamentador também repete a lei, determinando que ao Ministério da Saúde, às Secretarias Estaduais, Distrital e Municipais de Saúde competirá:

"adotar e aplicar normas de funcionamento às instituições geriátricas e similares, com fiscalização pelos gestores do Sistema Único de Saúde (art. $9^{9}, \mathrm{IX}$ ).

Mas é preciso ressaltar que em um e outro caso teriamos instituições geriátricas, isto é, destinadas ao tratamento dos males e enfermidades da ancianidade. Ou, nos termos da Portaria n. 810, "destinadas a atender as necessidades de cuidados com a saúde", as quais não podem ser confundidas com instituições asilares. É significativo para esse entendimento o disposto no art. $4^{2}$, parágrafo único:

"Art. $4^{\circ}$ Constituem diretrizes da política nacional do idoso:

Parágrafo único. É vedada a permanência de portadores de doenças que necessitem de assistência médica ou de enfermagem permanente em instituições asilares de caráter social".

O Decreto Regulamentador n. 1.948/96 declina os motivos da proibição, pois que a falta de tais serviços poderia "agravar ou pôr em risco sua vida (do idoso enfermo) ou a vida de terceiros" - art. 18.

Esse diploma normativo estabelece a diferença entre atendimento asilar e não asilar, prevendo as formas alternativas ou intermediárias entre a assistência dentro da família ou em seus lares, preferencial pelo próprio comando constitucional - art. 230, $\S 1^{2}$ - e a institucionalização, asilamento. Preconiza a criação de formas alternativas ao atendimento asilar: centros de convivência, centros de cuidados diurnos, casa-lar e oficina abrigada de trabalho, atendimento domiciliar e, num momento de humildade do legislador e de reconhecimento da capacidade criadora da sociedade, outras formas de atendimento "surgidas na própria comunidade, que visem à promoção e à integração da pessoa idosa na família e na sociedade".

No que tange aos serviços de saúde, o Decreto também possui a mesma característica da alternatividade, de plurais formas de atendimento, estimulando, no próprio Sistema Único de Saúde, a criação de Hospitais-Dia, Centros-Dia e Atendimento Domiciliar para o idoso. Enfatiza-se a participação da sociedade na promoção da saúde, porém se comete inequivocamen- 
te ao SUS a responsabilidade de "garantir ao idoso a assistência integral à saúde, entendida como o conjunto articulado e contínuo das ações e serviços preventivos e curativos, nos diversos niveis de atendimento". Não poderia ser de forma diversa, pois a saúde do idoso não é outra coisa senão aspecto particular, segmento, da saúde em geral, devendo obedecer aos mesmos princípios e diretrizes constitucionais para esta reservado.

No que se refere às instituições asilares, visando operacionalizar a vedação determinada na lei que regulamenta, o decreto determina ainda que a avaliação médica pelo serviço de saúde local é que determinará a permanência ou não do idoso enfermo na instituição asilar, sendo que esta poderá firmar contrato ou convênio com o sistema para o fim de implementar essa condição.

Podemos deduzir que a forma asilar de assistência ao idoso, que, sim, envolve 0 atendimento às necessidades de saúde do asilado, está longe de ser a mais desejável. Sem dúvida não é a que resulta em maiores benefícios à saúde integral do idoso, mas é forçoso reconhecer constituir-se em forma da qual a sociedade ainda não conseguiu emancipar-se.

Como decorre da própria Lei n. 8.842, há inúmeras formas de promover a saúde do idoso; a imposição de contratação de pessoal habilitado aos asilos, especialmente os de natureza filantrópica, poderia até ser uma delas, mas certamente não a mais racional, a que possa produzir os melhores resultados, ou a mais consonante com a filosofia de atendimento que informa a política nacional adotada para o idoso. Está, isto sim, na contramão do projeto que a legislação protetora que citamos visa implementar.

Se entendêssemos a Portaria n. 810 na forma como pretendida pela autoridade coatora, teríamos de reconhecer uma inconstitucionalidade formal, já que a norma infralegal estaria impondo obrigação que apenas à lei caberia impor. Nesse sentido a normação veiculada pela Portaria, por sinal, anterior aos diplomas que analisamos, não encontraria neles o necessário fundamento de validade. A Lei e o Decreto Regulamentador, que the são hierarquicamente superiores no ordenamento, determinam, de fato, a elaboração e aplicação, pela autoridade sanitária, de normas de funcionamento das instituições geriátricas e similares. Normas cuja infração autorizaria a aplicação, ainda pela autoridade sanitária, das sanções cominadas no art. 10 , inciso XXIX, da Lei n. 6.437/77. Não está autorizada pela lei, no entanto, a extensão da disciplina em relação a instituições outras, que, sim, dão assistência ao idoso, porém não na área de saúde.

Não havendo previsão legal, e de fato não há, não há como impor a contratação de profissional enfermeiro ao tipo de instituição de que tratamos. 


\section{A RAZOABILIDADE ADMINISTRATIVA, A COLABORAÇÃO COM O ESTADO E O CONTROLE PELO ESTADO}

A maior fragilidade da saúde do idoso e a necessidade de prevenir casos de desatenção, lamentavelmente encontráveis em instituições do tipo que analisamos, poderiam inclinar-nos no sentido da admissão de uma maior ingerência do Poder Público nas mesmas, no sentido pretendido pelo COREN.

Fora de dúvida a atenção de profissionais não só da enfermagem, como nutricionistas, terapeutas recreacionais, psicólogos, etc., sobretudo para atuar no campo preventivo, seria de todo conveniente e desejável em qualquer instituição do tipo ou assemelhada àquela que impetra o Mandado de Segurança, colaboradora do Estado na execução de seus objetivos. A questão, porém, é saber a forma como essa atenção será ministrada e a exigência por parte do Poder Público dessas condições, que diríamos ideais.

A colaboração dessas entidades com o Estado não se dá meramente no aspecto da assistência social, mas também no da saúde. Não podemos esquecer que o asilo, ou seja, a moradia, assistência, lazer e convivência oferecida de modo supletivo à assistência familiar e em moldes a privilegiar a dignidade da pessoa humana, oferecendo privacidade, assistência adequada, etc., por compor os requisitos para que se atinja melhor qualidade de vida também compõe os requisitos necessários à promoção da saúde, em sua concepção mais ampla, sistêmica (Schwartz: 2001).

Seria justo, então, que, por oferecer o minus, se exigisse dessas entidades também o plus, condicionando-Ihe de forma mais estrita o modo de exercer suas atividades? Em que escala?

Parece que a resposta pode ser dada pelo critério da proporcionalidade e da razoabilidade. Vejamos.

"A atividade do Estado sempre pode trazer um sacrifício a alguns em beneficio da coletividade. Mas tanto a Lei, que prevê e autoriza o sacrifício, quanto a administração, que aplica a lei concretamente, devem se limitar e cuidar para que o sacrificio imposto seja proporcional à vantagem geral obtida" (Santos, 1999).

Maria Sylvia Zanella Di Pietro, citando Agustín A. Gordillo e Diogo de Figueiredo Moreira Neto. coloca a aplicação dos princípios da razoabilidade e da proporcionalidade no campo da discricionariedade administrativa, como forma de limitá-la:

"Trata-se de principio aplicado ao direito administrativo como mais uma das tentativas de impor-se limitações à Discricionariedade administra- 
tiva, ampliando-se o âmbito de apreciação do ato administrativo pelo Poder Judiciário.

embora a norma legal deixe um espaço livre para a decisão administrativa, segundo critérios de oportunidade e conveniência, essa liberdade às vezes se reduz no caso concreto, onde os fatos podem apontar para o administrador a melhor solução. Se a decisão é manifestamente inadequada para alcançar a finalidade legal, a Administração terá exorbitado dos limites da discricionariedade e o Poder Judiciário poderá corrigir a ilegalidade" (Di Pietro, 2000).

Celso Antônio Bandeira de Mello comina de ilegalidade a conduta em desrespeito ao princípio:

"Este princípio enuncia a idéia - singela, aliás, conquanto freqüentemente desconsiderada - de que as competências administrativas só podem ser validamente exercidas na extensão e intensidade proporcionais ao que seja realmente demandado para cumprimento da finalidade de interesse público a que estão atreladas.

Sobremodo quando a Administração restringe situação jurídica dos administrados além do que caberia, por imprimir às medidas tomadas uma intensidade ou extensão supérfluas, prescindendas, ressalta a ilegalidade da conduta. É que ninguém deve estar obrigado a suportar constrições em sua liberdade ou propriedade que não sejam indispensáveis à satisfação do interesse público" (Mello, 1997).

O princípio, como elucidado pelos doutrinadores acima, é de todo aplicável ao caso. À luz do quanto exposto: cabe, sem dúvida alguma, a fiscalização das condições mínimas de assistência, à saúde inclusa, praticadas nos asilos para idosos, porém não deve esta ser exercida de forma a pretender impor aos mesmos ônus maiores do que aqueles razoáveis e suportáveis, sob pena de, inviabilizando-os, redundar a medida em prejuízo do interesse público visado, que é, em última análise, a disponibilização da assistência adequada, em seus múltiplos aspectos, aos idosos.

O Ministério Público em sua manifestação no bojo do processo, alertou para o fato de que:

"O Direito Político Contemporâneo, mais precisamente na área da Administração Pública, em face da defasagem estatal do Estado do BemEstar Social, tem revelado uma tendência irreversivel no rumo da despolitização, na forma da pluralização dos interesses, da subsidiariedade e da delegação social", 
e que:

"Fruto da descentralização social, insta ressaltar a existência das organizações sociais chamadas de sociedades de colaboração, organizações especialmente vocacionadas a travar parcerias com o Poder Público para atividades de interesse coletivo".

Questionando-se:

"Nesse sistema de parceria, de colaboração com o Estado, para a consecução de atividades de inerente interesse público, estaria obrigada à sujeição do poder regulador estatal no que tange à contratação de enfermeiros?"

A essas considerações aduzimos o fato de que, se o amparo ao idoso está entre aqueles valores, ao lado dos atinentes à criança e adolescente, educação, meio ambiente, etc., a que, por sua natureza e relevância, houve por bem o Constituinte atribuir os deveres e responsabilidades pela sua preservação não só ao Estado, mas também à família e à sociedade, art. 230; a assistência à saúde, a despeito de a Constituição franqueá-la também à iniciativa privada, art. 199, caput, é dever cometido com exclusividade ao Estado, art. 196. Dever este, conforme assente na doutrina e jurisprudência, de conteúdo não meramente relativo, mas, pelo contrário, de conteúdo absoluto, correspondente à contraposição de um direito subjetivo de todo cidadão a uma obrigação correlata do Estado, com sanção pelo não-cumprimento.

Concordamos com a conclusão do ilustre representante do Ministério Público Federal. De fato, a organização de colaboração de que tratamos "não tem - e não deve ter - a pretensão de suprir todas as deficiências do Estado". Não tendo a finalidade de atendimento na área da saúde, mas limitando sua finalidade a propiciar lar aos idosos, não deve dela ser exigida aquela prestação.

Por outro lado, acrescemos que ainda que a função reguladora seja, a nosso ver, indeclinável, mormente em sede de direito tão inapelavelmente ligado aos direitos fundamentais à vida e à dignidade, como é o direito à saúde, não podemos admitir que o Estado, a pretexto de exercê-la, imponha ônus indevido à sociedade, aqui representada na instituição beneficente. Não pode o Estado pretender, ainda que indiretamente, eximir-se de sua obrigação constitucional de prover a assistência à saúde, exigindo dessa sociedade a prestação que, em última análise, a ele compete.

\section{CONCLUSÃO}

Posto que a assistência à saúde constitua direito de todos e obrigação imposta ao Estado (CF, art. 198), também e com mais razão, em face das 
fragilidades próprias ou freqüentes à condição do idoso, deve ser esperada, promovida e também exigida em face dos asilos destinados ao seu abrigo.

Posto que, sim, prestam serviços que vêm a compor em parte a promoção da saúde entendida em seus aspectos mais amplos, não poderiamos, entretanto, efetivamente, considerar os serviços de saúde como inerentes a tais instituições.

A legislação sanitária preconiza formas plurais de oferecimento da atenção em saúde ao idoso, diretriz que de resto informa outros segmentos da atenção à saúde, como é o caso, por exemplo, da atenção ao portador de distúrbios mentais. No caso, não podemos confundir as instituições destinadas à moradia e convivência do idoso com instituições destinadas à assistência à sua saúde, sob pena até de, estigmatizando aquelas, frustrarmos sua função específica dentro do amplo espectro das ações que devem compor a promoção da saúde em sua integralidade.

Ainda que desposássemos ponto de vista diverso, há que se reconhecer que qualquer imposição da espécie que constituiu o objeto do caso analisado teria de partir da lei e, em partindo da lei, ser aplicada por órgão competente da autoridade sanitária. Efetivamente, à luz do quanto exposto em nossa análise, não foi o caso do ato administrativo impugnado.

\section{REFERÊNCIAS BIBLIOGRÁFICAS}

BASTOS, Celso. Hermenêutica e interpretação constitucional. São Paulo: Celso Bastos Editor/Instituto Brasileiro de Direito Constitucional, 1997.

BRASIL. Constituição (1988). Constituição da República Federativa do Brasil. 24⿳亠丷厂 ed. São Paulo: Saraiva, 2000.

DI PIETRO, Maria Sylvia Zanella. Direito Administrativo. $12^{\mathfrak{a}}$ ed. São Paulo: Atlas, 2000.

MARTINS JUNIOR, Wallace Paiva. "A discricionariedade administrativa à luz do princípio da eficiência". In: Revista dos Tribunais. São Paulo: Revista dos Tribunais, ano 90, v. 789, jul. 2001.

MELLO, Celso Antônio Bandeira de. Curso de Direito Administrativo. $9^{\mathbf{a}}$ ed. São Paulo: Malheiros, 1997.

SANTOS, Geraldo Borges. "Principios da Administração Pública”. In: Diké - Revista Juridica do Departamento de Ciências Juridicas da Universidade Estadual de Santa Cruz - UESC, ano I, llhéus, 1999.

SCHWARTZ, Germano André Doederlein. "Direito à Saúde: Abordagem Sistêmica, Risco e Democracia". In: Revista de Direito Sanitário, CEPEDISA, vol. 2, n. 1, São Paulo, março/2001. 